\author{
Proceedings of the $10^{\text {th }}$ International Conference on Applied Informatics \\ Eger, Hungary, January 30-February 1, 2017. pp. 303-307 \\ doi: 10.14794/ICAI.10.2017.303
}

\title{
Using the Flipped Classroom Method in Primary Education Informatics Classes
}

\author{
Hajnalka Torma \\ ELTE IK \\ hajnalka.torma@gmail.com
}

\begin{abstract}
It is not easy to be an Informatics teacher in a primary school in Hungary today: the low number of Informatics lessons is accompanied by a huge material to be covered. The flipped classroom method could be a solution to overcome this situation. Flipping the classroom means that the instruction is delivered online outside of class, while the classes are dedicated to practice, active learning and problem solving activities. With the spread of mobile devices among students, the method could be implemented more widely. In my paper, I am going to shortly introduce the flipped classroom management method. Next, I am going to present how I used the method to teach the topic of Internet search to $6^{\text {th }}, 7^{\text {th }}$, and $8^{\text {th }}$ grade students, where only the method of instruction was different, the practice tasks and available resources for students were the same. The effectiveness of the method was measured by a post test in both the flipped and control groups. The results of the test are going to be presented in the last part of the paper.
\end{abstract}

Keywords: computer science education, flipped classroom

MSC: 97Q60

\section{Introduction}

The traditional classroom is often criticized for being the stage for only passive learning opportunities, and students spending a lot of time on listening to teacher instruction instead of actively taking part in the learning process. The ideas of flipped classroom and flipped learning emerged from the need to change this traditional classroom setting. The most simplified definition of the flipped classroom says that school work and home work are inverted: school work is done at home, while home work is dealt with in school. A more elaborate definition by Brame defines flipped classroom as "a reversal of traditional teaching where students gain first exposure to new material outside of class, usually via reading or lecture videos, 
and then class time is used to do the harder work of assimilating that knowledge through strategies such as problem-solving, discussion or debates" [1]. From this definition, many teachers apply only the online lecture videos when trying to implement the flipped classroom, and less emphasis is put on what should be going on in the classroom. That was one of the reasons why the Flipped Learning Network started to draw attention to the difference between flipped classroom and flipped learning, and defined flipped learning as "a pedagogical approach in which direct instruction moves from the group learning space to the individual learning space, and the resulting group space is transformed into a dynamic, interactive learning environment where the educator guides students as they apply concepts and engage creatively in the subject matter" [2]. They claim that a flipped classroom does not necessarily lead to flipped learning. To engage in flipped learning a teacher must incorporate the four pillars of F-L-I-P (flexible environment, learning culture, intentional content, professional educator) into their practice. Using the flipped learning definition of Flipped Learning Network, the teacher has to choose the appropriate content for their students based on students' needs and skills, and make this content available for them to access on their own (see [3]). In higher education, online videos are now widely used in flipped classrooms instead of lectures, and lecture time is dedicated to actively working with the material, and engaging in meaningful activities (see [4] [5]). The question arises whether online videos can be as effective as frontal instruction in conveying basic content information at the elementary school level, where students are used to the teacher being in the centre.

\section{Research description}

The study took place in a primary school in Budaörs, Hungary. The school follows the suggested curriculum framework based on the National Hungarian Curriculum regarding the teaching of Informatics, so students have 1 Informatics lesson a week from $6^{\text {th }}-8^{\text {th }}$ grade. Students were learning in a gamified learning environment, which means that they got experience points for their achievements, for completing tasks and writing tests. Being their instructor, the writer of this paper tried to follow the four pillars of flip when planning classwork even before this study, so students were more used to individual and group work in Informatics classes than frontal instruction. In order to carry out the research study, all the classes from different grades dealt with the same topic (searching on the Internet) for a month during the 2016 fall semester. Some of the groups were chosen to get instruction through online videos as homework, while the control groups got teacher-centred instruction during classes. Both groups were provided some readings as well, but whether students had used those readings was not examined. The online videos and readings were shared through the gamified learning management system, which was familiar to students. Some online videos contained questions to test understanding while students were watching the videos. Figure 1 shows the number of students who took part in the study, and the distribution of students among the flipped and non-flipped groups. Altogether there were 132 students: 83 in the flipped groups 
and 49 in the control groups.

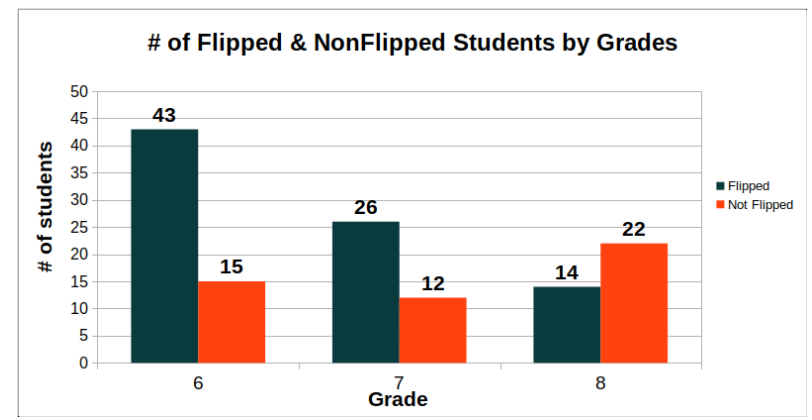

Figure 1: The number of students in flipped and non-flipped groups

Both the flipped and the control groups were given the same practice tasks during class time. Some practice tasks were designed for individual work and some for group work. The teacher was always present to give guidance and help when needed, but students were also asked to help each other when they had problems. As in the flipped groups the content was assigned as homework, there was more time to spend on tasks, and there remained time for group Boss Fights in the gamified learning environment. Moreover, the teacher was able to deal with those students, who usually need more attention and help during classwork. Students had to upload their work after each lesson to the learning management system. This enabled the teacher to give immediate feedback after each lesson. Moreover, some parts of the online explanations seemed insufficient, so a new animated explanation video was uploaded for the students in the flipped groups.

To measure the differences between the flipped and control groups, a post-test was administered in each group. The post-test contained simple (for 50 points) and more complex tasks (for 130 points) that directly measured the students' skills at searching the Internet and using online maps.

\section{Results and discussion}

The results of the post-test are shown in Figure 2. As one can see, the difference between the averages of the results between the flipped and control groups is not significant (t-test $\mathrm{p}=0,7393$ (Grade 6), $\mathrm{p}=0,8359$ (Grade 7), $\mathrm{p}=0,0837$ (Grade 8).

The examination of the results of simple and more complex tasks showed that there is a slight difference between the results of $8^{\text {th }}$ grade students in the flipped and the control groups (t-test $\mathrm{p}=0,0671$ ), but there is no statistically significant difference in other grades regardless of task types. See Figure 3 and Figure 4.

These results show that the online videos were as effective in conveying content to students as frontal instruction lead by the teacher in this study environment. The immediate feedback and the customization of the content along the learning 


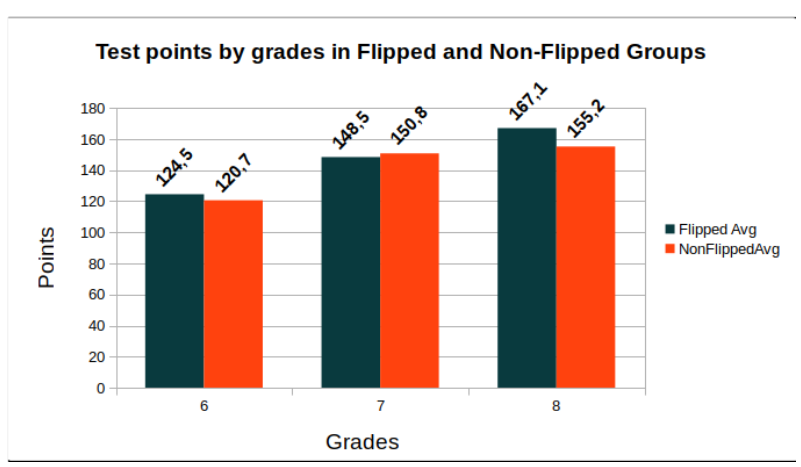

Figure 2: The results of the post-test

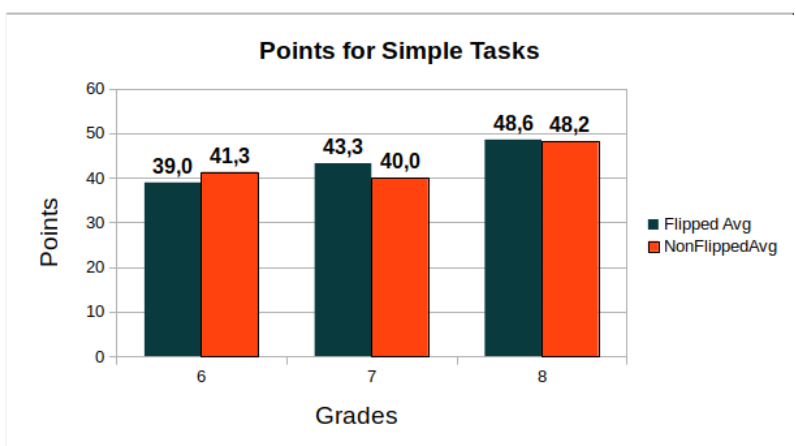

Figure 3: Results of simple tasks of the post-test by grade

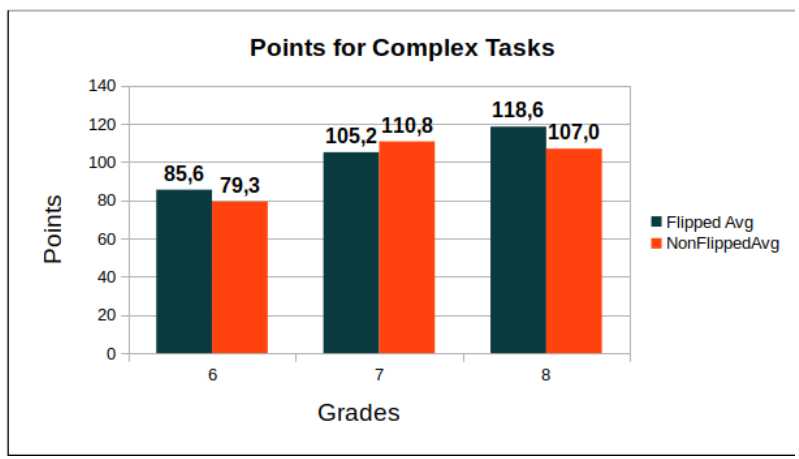

Figure 4: Results of complex tasks of the post-test by grade

process (providing an additional explanation video) enabled students to be able to cope with activities in the classroom, as if they had been given teacher-centred instructions. The findings are also supported by the results of students from dif- 
ferent grades. Students from $6^{\text {th }}$ grade had significantly less points both in flipped and non-flipped classes than students from the $8^{\text {th }}$ grade, which is what a teacher would expect due to differences in their mental maturity.

The study environment was built on the 4 Pillars of FLIP when class activities and student-teacher roles were planned. In this environment, the form of content delivery seems to be of less importance. However, thanks to online videos there was more time for practice tasks during classes. This means that choosing the appropriate online content for students as homework could free up valuable classroom time, which corresponds to the basic idea behind the flipped classroom.

\section{Conclusion}

The study shows that the flipped classroom could be used in Informatics classes in an elementary school environment: the carefully chosen online content could replace the teacher's frontal instruction. Further study is needed to determine what classroom activities should be used together with online content to achieve the aims of an Informatics class, to improve students' procedural fluency and computational thinking skills, and to realize differentiation based on students' needs.

\section{References}

[1] Brame, C., Flipping the classroom. Vanderbilt University Center for Teaching., (2013) Retrieved [2017.01.05.] from http://cft.vanderbilt.edu/ guides-sub-pages/flipping-the-classroom/.

[2] Flipped Learning Network (FLN), The Four Pillars of F-L-I-P ${ }^{\mathrm{TM}}$, (2014). Retrieved [2017.01.05.] from https://flippedlearning.org/wp-content/uploads/ 2016/07/FLIP_handout_FNL_Web.pdf.

[3] Hamdan, N., McKnight P., K. McKnight K., Arfstrom, K. M., A review of flipped learning. Flipped Learning Network, (2013).

[4] Bishop, J. L., Verleger, M. A., The flipped classroom: A survey of the research, ASEE National Conference Proceedings, Atlanta, GA. Vol. 30 No. 9. (2013).

[5] O'Flaherty, J., Phillips, C., The use of flipped classrooms in higher education: A scoping review, The Internet and Higher Education. Vol. 25 (2013), 85-95. 